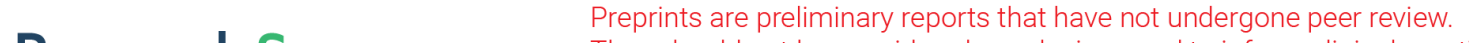 They should not be considered conclusive, used to inform clinical practice, or referenced by the media as validated information. \\ Active Coolant Control Onto Thermal Behaviors of Precision Ball Screw Unit
}

\author{
Teng Liu \\ Hebei University of Technology \\ Chentao Li \\ Hebei University of Technology \\ Yifan Zhang ( $\square$ van_email@163.com ) \\ Hebei University of Technology

\section{Weiguo Gao} \\ Tianjin University

\section{Zhikai Fu} \\ Tianjin University \\ Jianjun Zhang \\ Hebei University of Technology \\ Dawei Zhang \\ Tianjin University
}

\section{Research Article}

Keywords: precision ball screw unit, thermal behaviors, active coolant control, thermal elongation, heatfluid-solid coupling

Posted Date: June 18th, 2021

DOI: https://doi.org/10.21203/rs.3.rs-630243/v1

License: (c) (1) This work is licensed under a Creative Commons Attribution 4.0 International License. Read Full License

Version of Record: A version of this preprint was published at The International Journal of Advanced Manufacturing Technology on December 1st, 2021. See the published version at https://doi.org/10.1007/s00170-021-08413-4. 


\title{
Active coolant control onto thermal behaviors of precision ball screw unit
}

\author{
Teng Liu ${ }^{1,2}$, Chentao $\mathrm{Li}^{1}$, Yifan Zhang ${ }^{2,3 *}$, Weiguo $\mathrm{Gao}^{2}$, Zhikai Fu², Jianjun Zhang ${ }^{1}$, and Dawei Zhang ${ }^{2}$ \\ ${ }^{1}$ School of Mechanical Engineering, Hebei University of Technology, Tianjin 300130, China \\ ${ }^{2}$ Key Laboratory of Mechanism Theory and Equipment Design of Ministry of Education, Tianjin University, \\ Tianjin 300355, China \\ ${ }^{3}$ School of Computer Science and Technology, Civil Aviation University of China, Tianjin 300300, China
}

\begin{abstract}
Being a critical factor affecting the motion accuracy of precision machine tools, structural thermal elongation of precision ball screw unit is generally caused by the comprehensive influence from heat generations of screw-nut pair / bearings and time-varying ambient temperature. To resist 2 thermal disturbances above to guarantee precisely the original length of screw shaft, an active coolant control strategy is proposed in this paper. This strategy is based on an empirical model: For the slender and long tubular structure of screw shaft, the screw shaft temperature is approximately equal to its recirculating coolant temperature. The reason is that the intensive forced coolant convection is capable of eliminating screw shaft temperature rises caused by friction heat generations and ambient air convections. Based on this premise, screw coolant temperature can be consistently controlled by an active strategy, further to correct the thermal elongation of screw shaft. It can be experimentally verified that the thermal variations of machine positioning accuracy caused by the active coolant control strategy are not more than $10 \mu \mathrm{m}$, which are lower than traditional strategy. Besides, based on detected structural temperatures of precision ball screw unit, the empirical model above is further proved to be reliable by FE simulation method.
\end{abstract}

Keywords: precision ball screw unit, thermal behaviors, active coolant control, thermal elongation, heat-fluid-solid coupling

*Email address of corresponding author: van_email@ 163.com 


\section{Introduction}

In recent decades, precision ball screw unit has been widely applied into linear feed systems of various precision machine tools, to convert rotational motion into linear motion [1]. Being the vital factor causing the thermal variations of machine accuracy, the shaft thermal elongation of precision ball screw unit is generally attributed to 2 disturbing factors from a machining activity, which is revealed in Fig. 1: (1) friction heat generations from screw-nut pair and bearing groups, and (2) air convective heat transfer with time-varying ambient temperature. For dissipating these disturbing heat transfers, the hollow channel for recirculating coolant is frequently adopted for the shaft design of precision ball screw unit.

Traditionally, the ambient temperature tracking strategy [2] is generally adopted to regulate supply temperature of screw recirculating coolants for precision machining activities. But the disadvantage of this strategy has been gradually exposed: Because coolant supply temperature is dynamically determined based on the ambient temperature detections, disturbing heat transfers onto the screw structure can hardly be dissipated accurately. This restricts the effectiveness of reducing structural thermal elongations of precision ball screw unit [2]. Therefore, it is urgent to develop an active strategy regulating coolant temperature to control thermal behaviors of precision ball screw unit, thus to guarantee precisely its original length for machine accuracy stability.

Many scholars have studied the thermal behaviors modeling of linear feed system of machine tools. On one hand, some scholars investigated the modeling method based on simulation technology. On the basis of finite element thermal analysis, Mao et al. [3] proposed an iterative finite element thermal analysis algorithm combining experimental data to calculate the convective heat transfer coefficient (CHTC) of precision ball screw system. Oyanguren et al. [4] presented a numerical modelling strategy to predict the preload variation due to temperature increase using a thermo-mechanical 3D finite element method (FEM)-based model for double nut-ball screw drives. Li et al. [5] applied finite difference method to simulate the temperature distribution and thermal growth of the ball screw feed drive system under various working conditions, and verified that the simulation accuracy could be improved by using the proposed method.

On the other hand, another part of scholars established experimentally the thermal model of machine linear feed system. Based on experimental data, Li et al. [6] proposed a new inverse 
random model by the combination of the stochastic theory, genetic algorithm, and radial basis function neural network (RBFNN). The aim is to predict ball screw system thermal errors, with the randomness of influencing factors being considered. Li et al. [7] put forward a prediction model for thermal errors of the lead screw considering the time-varying heat generation rate of each heat source, with the combination of numerical and experimental methods. Li et al. [8] proposed an adaptive moving thermal network model of screw system with moving thermal excitation under variable experimental conditions and a real-time prediction method for the thermal errors of this system. Shi et al. [9] proposed a Bayesian neural network modeling method based on thermal error detections of machine feed system, which has higher prediction accuracy and multi-condition adaptability than the BP neural network and multiple linear regression model. Gao et al. [10] superimposed the geometric error model based on coordinate rotation transformation and the thermal error model based on BP neural network to obtain a comprehensive model to predict the positioning errors of the linear feed system. Yang et al. [11] used the Elman neural network (ENS) optimized by the differential evolution (DE) algorithm to model the thermal errors of the two-axis differential micro-feed system (TDMS), which is proved to be accurate and robust. The researching activities above mainly focus on the thermal model establishments to accurately predict thermal behaviors of machine feed system, providing preparations for the accuracy guarantee of precision machine tools.

Based on the published investigations above onto thermal modeling of machine feed systems, there are still other studies placed emphasis on suppression methods of machine thermal errors. Zaplata et al. [12] established the temperature distribution of ball screw-pair by using the partial differential equation (PDE) model, and measured the temperature distribution of CNC axis online during the operation, to realize the machine thermal error compensation. Shen et al. [13] proposed an offset compensation method by CNC-PLC technology, which adopted Bayesian Networks to predict thermal errors. Experiments show that this technology can reduce more than $70 \%$ of the machining error caused by thermal deformation. Bosetti et al. [14] proposed an active error compensation method for positioning errors, which can be realized by real-time measurement onto the displacement field of a given structural component without establishing any model of its dynamic/thermal structure behaviors. Based on the thermal deformation balance principle, Ge et al. [15] used carbon fiber reinforced plastics (CFRPs) with the negative linear expansion coefficient to realize thermal deformation compensation for functional parts of precision machine tools. Wei et al. [16] proposed a method to reduce the influence of thermal deformation onto the EM 
performance of small APAAs via real-time compensation, which has the high prediction accuracy. And the decrease in EM performance caused by antenna panel thermal deformation is effectively reduced. Most of these studies on thermal error suppression of machine feed system relied on the compensation method, whose main idea is to create an opposite error to eliminate thermal errors of machine feed system [17]. Nevertheless, there are few achievements on the thermal elongation correction of precision ball screw unit by no method other than its coolant temperature control.

Our earliest research developed an active coolant strategy [18] based on the combination of extreme learning machine (ELM) and genetic algorithm (GA) to control spindle thermal balance, thus to achieve a comprehensive and accurate suppression onto spindle thermal errors. Furthermore, for the thermal perception and control onto spindle bearings without spindle/bearing structural modifications for built-in thermal sensors, a thermal simulation speculation-based active coolant control strategy [19] onto spindle bearings was proposed to guarantee spindle accuracy. However, these strategies are applicable exclusively to machine spindle units, but can hardly guarantee the thermal balance of precision ball screw unit.

For this problem, this paper proposes an active coolant control strategy onto thermal behaviors of precision ball screw unit, based on the differentiated multi-loop bath recirculation system [20]. This strategy keeps the recirculating coolant temperature stable, thus to eliminate temperature rise and thermal elongation of screw shaft. The organization of this paper is as follows: Section 2 describes the active coolant control principle onto thermal behaviors of precision ball screw unit and its premise hypothesis (empirical model): screw shaft temperature is dynamically equal to coolant temperature. To clarify the validity of the proposed active coolant control strategy, Section 3 verifies this empirical model by the numerical simulation method. Section 4 clarifies advantages of the proposed active thermal control strategy for precision ball screw unit based on experimental and simulation results. Eventually, Section 5 gives conclusions of the whole research.

\section{Active coolant control principle onto thermal behaviors of precision ball screw unit}

\subsection{Thermal balance - temperature variation - thermal elongation of precision ball screw unit}

Because the motor assembly surface of motor-bearing seat is generally equipped with insulation material (revealed in Fig. 1), the thermal influence from motor heat generation onto precision ball screw unit can be ignored. Therefore, as shown in Fig. 2, the structural temperature variation of 
1 precision ball screw unit in operation state is mainly affected by the friction heat generations of screw-nut pair / bearings, air convection with the time-varying ambient temperature and the heat dissipations from recirculation coolant. According to thermoelastic law [21], the structural thermal elongation $f(\mu \mathrm{m})$ of precision ball screw unit is generated based on its temperature variation, with the time-lag effect:

$$
f=\alpha \Delta T
$$

In equation (1), $\alpha$ is the thermal expansion coefficient of screw shaft material $\left(\mathrm{K}^{-1}\right), \Delta T$ is the structural temperature rise of precision ball screw unit $\left({ }^{\circ} \mathrm{C}\right)$.

It can be concluded from equation (1) that, the thermal elongation of screw shaft $f$ can be theoretically eliminated by stabilizing its structural temperature rise $(\Delta T=0)$. According to heat transfer theory, that needs a dynamic power balance between screw structural heat generations / ambient air convection and coolant heat dissipations, which must be based on an active coolant control strategy onto thermal behaviors of precision ball screw unit.

\subsection{Active coolant control strategy for thermal behaviors of precision ball screw unit}

\subsubsection{Empirical model for active coolant control strategy}

Due to the movement of screw nut along the screw shaft, the RTD sensor attachment for screw shaft temperature monitoring can cause interference between screw nut and RTD sensor. Therefore, the temperature monitoring onto the screw shaft for this active coolant control strategy is proposed based on the recirculating coolant temperature monitoring.

The strategy realization must be relied on a premise hypothesis (an empirical model): For the slender and long tubular structure of screw shaft, the screw shaft temperature can be dominantly determined by its recirculating coolant temperature, owing to the intensive coolant forced thermal convection onto screw shaft:

$$
T_{\mathrm{scr}}=T_{\text {coo }}
$$


In equation (2), $T_{\text {coo }}$ is the screw coolant temperature $\left({ }^{\circ} \mathrm{C}\right)$, and $T_{\text {scr }}$ is the screw shaft temperature $\left({ }^{\circ} \mathrm{C}\right)$. Then the reliability of this empirical model is verified in Section 4.2.2.

\subsubsection{Description of active coolant control strategy}

Based on the empirical model above, the active control strategy onto structural thermal behaviors of precision ball screw unit is realized by the closed loop temperature controls onto its recirculating coolant, which is described in Fig. 3: the initial inlet / outlet temperatures $T_{\text {in }}(0) / T_{\text {out }}(0)$ of screw coolant are recorded. Their average value $T_{\mathrm{coo}}(0)$ is used as the control target. During the operation of machine feed system, the coolant average temperature at each moment $T_{\operatorname{coo}}(\tau)$ is continuously monitored and compared with the control target $T_{\operatorname{coo}}(0)$, to obtain the relative temperature:

$$
\Delta T_{\text {coo }}(\tau)=T_{\text {coo }}(\tau)-T_{\text {coo }}(0)
$$

The calculated relative temperature value $\Delta T_{\text {coo }}(\tau)$ is transmitted to the control algorithm to dynamically generate instructions to regulate coolant supply temperature at the next moment $\tau+1$. Consequently, the average temperature of screw coolant is kept stable during the whole operation process.

Because the screw shaft temperature is empirically equal to coolant temperature, this strategy can resist disturbances from internal heat generations and external heat convection of precision ball screw unit onto its structural temperature. Then the screw thermal elongation can be actively corrected by the stabilization onto screw shaft temperature.

Specially, the closed loop BP-PID algorithm [22] is adopted in this paper for the stabilization control onto the screw coolant temperature. As depicted in Fig. 3, closed loop PID algorithm is utilized to eliminate continuously the relative temperature of screw coolant $\Delta T_{\text {coo. Besides, based }}$ on the BP neural network, PID parameters $K_{\mathrm{P}} / K_{\mathrm{I}} / K_{\mathrm{D}}$ are optimally adjusted according to detections onto screw coolant temperature.

\subsubsection{Experimental platform for active coolant control strategy}

In order to realize the active coolant control strategy onto thermal behaviors of precision ball screw unit above, the experimental platform must be constructed based on necessary RTD sensors 
and differentiated multi-loop bath recirculation system [20]: As revealed in Fig. 4, RTD sensors are installed at screw coolant channel inlet and outlet to monitor coolant temperature, and another RTD sensors are mounted nearby heat generating parts (bearings and screw-nut pair) to detect structural temperature rises of precision ball screw unit.

Meanwhile, as shown in Fig. 5, independent coolant blenders are connected to the coolant channels of 2 precision ball screw units of machine feed system. This makes the differentiated multi-loop bath recirculation system realize dynamic supply temperatures onto its left and right screw coolants, according to the received instructions from the controlling module of host computer software.

Based on the preparations above, the experimental platform for active coolant control strategy is constructed according to the principle in Fig. 6: When the machine feed system is in operation, screw coolant temperature signals detected by RTD sensors are continuously collected to trigger the PID-BP algorithm in the controlling module of host computer software. Then coolant supply temperature instructions are dynamically calculated, and then transmitted to the differentiated multi-loop bath recirculation system to perform. Thus the left and right screw coolant temperatures of machine feed system can be stabilized according to the obtained instructions above.

On the other hand, screw heat generating part temperatures detected by RTD sensors are used to construct the optimization objective function in Section 3.2.2. The detected signals are displayed in monitoring module of host computer software.

\section{Empirical model verification method of active coolant control onto thermal behaviors of} precision ball screw unit

\subsection{Thermal numerical simulation method of precision ball screw unit}

\subsubsection{Heat-fluid-solid coupling analytical model}

To verify the reliability of the empirical model proposed in Section 2.2.1, it is necessary to numerically simulate temperature characteristics of precision ball screw unit, which are influenced by heat generations of screw-nut pair / screw bearings, heat dissipation of screw circulating coolant and ambient air convection. The heat - fluid - solid coupling simulation model of precision ball 
1 screw unit is established by finite element (FE) method. By solving equation (4) [23], the heat

2 transfer process and fluid-solid coupling heat transfer can be obtained:

3

$$
\frac{\partial}{\partial t}\left(\rho_{\text {oil_sol }} H_{\text {en }}\right)+\nabla \bullet\left[\vec{v}\left(\rho_{\text {oil_sol }} H_{\text {en }}+p\right)\right]=\nabla \bullet\left[k_{\text {oil_sol }} \nabla T+(\vec{\tau} \vec{v})\right]+S_{\mathrm{h}}
$$

For equation (4), $\rho_{\text {oil_sol }}$ is the density of coolant oil or solid structure $\left(\mathrm{kg} / \mathrm{m}^{3}\right), k_{\text {oil_sol }}$ is the thermal conductivity of coolant oil or solid structure $(\mathrm{W} /(\mathrm{m} \cdot \mathrm{K})), H_{\mathrm{en}}$ is the energy content per unit mass $(\mathrm{J})$, $p$ is the pressure $\left(\mathrm{P}_{\mathrm{a}}\right), \begin{aligned} & \mathrm{r} \\ & \mathrm{v} / \tau\end{aligned}$ volumetric heat source $(\mathrm{W}), \nabla \bullet\left(\begin{array}{l}=\mathrm{r} \\ \tau \nu\end{array}\right)$ is the viscous power dissipation of flowing coolant (W), $\nabla \bullet(k \nabla T)$ is the heat transfer among solid, flowing coolant and ambient air (W).

Meanwhile, the flow field is obtained by FE method. Since the coolant is in a laminar flow state and is assumed to be a steady-state viscous incompressible fluid, the flow field is calculated by solving equation (5):

$$
\left\{\begin{array}{l}
\frac{\partial u}{\partial x}+\frac{\partial v}{\partial y}+\frac{\partial w}{\partial z}=0 \\
\frac{\partial}{\partial t}\left(\rho_{\text {oil }} \vec{v}\right)+\nabla\left(\rho_{\text {oil }} \vec{v} \vec{v}\right)=-\nabla p+\nabla\left(\begin{array}{l}
= \\
\tau
\end{array}\right)
\end{array}\right.
$$

In equation (5), $u / v / w$ is the coolant flowing velocity on $\mathrm{X} / \mathrm{Y} / \mathrm{Z}$ direction $(\mathrm{m} / \mathrm{s})$, and $\rho_{\text {oil }}$ is the density of coolant oil $\left(\mathrm{kg} / \mathrm{m}^{3}\right)$.

Based on this mathematical model above, the transient temperature behaviors of precision ball screw unit can be solved by numerical simulation.

\subsubsection{Numerical simulation method}

For the transient heat-fluid-solid coupling simulation of precision ball screw unit, its geometry model is constructed in ANSYS. Then SOILD5 unit is adopted for meshing the bearing balls and screw / nut structures of precision ball screw unit. SOILD70 unit is adopted for meshing other structures. A total of 41803 nodes and 174867 grid units are generated, respectively. FLUID116 
unit, which for heat conduction and fluid transmission between two nodes, is selected as the coolant fluid unit for meshing. The surface effect unit between the coolant and inner wall of screw coolant channel is set as SURF152 to realize the convective heat transfer effect in simulation. Based on the structural meshing of precision ball screw unit, physical parameters of its solid structure and fluid regions are defined according to Tab. 1.

Specially, in order to realize the full stroke reciprocating motion of screw nut along the screw shaft in transient thermal simulation, the following setting is adopted: Firstly, because the duration required for the precision ball screw unit to reach its structural thermal stability in operation is empirically 2 hours, 7200s is selected as the total time length of its transient heat-fluid-solid coupling simulation. In addition, owing to the screw nut reciprocating at $9 \mathrm{~m} / \mathrm{min}$ during the experiment (Section 4) in this paper, the substep length of one-way relative movement of screwnut pair is calculated as $6 \mathrm{~s}$, with the screw stroke length being considered. APDL is used to define different displacement endpoint coordinates of screw nut for each substep in transient simulation. Based on the method above, the cyclic reciprocating linear motion of screw-nut pair is realized in transient simulation.

For the meshed simulation model, heat generation loads of screw-nut pair / bearing groups are loaded according to Fig. 7, and convective heat transfer coefficients of ambient air and recirculating coolant are then loaded onto the outer surfaces of screw structure and inner wall of coolant channel respectively. The time-varying ambient temperature is considered into simulation model according to its measured data. Most vitally, to simulate actual structural thermal behaviors of precision ball screw unit under different coolant control strategies, the coolant supply temperature data tested in experiments are utilized as the screw coolant inlet temperature conditions for simulations.

For the transient thermal simulation of precision ball screw unit, heat generation and convective heat transfer coefficients should be calculated and corrected by the following method.

\subsection{Thermal load modeling and optimization correction method}

\subsubsection{Thermal load modeling}

\subsubsection{Screw bearings}


While the screw bearings are in motion, friction heat was generated by the relative movements between the various parts of the bearing. The heat can be computed by the equation (6) [24]:

$$
Q_{\mathrm{b}}=1.047 \times 10^{-4} n\left(M_{0}+M_{1}\right)
$$

In equation (6), friction torque $M_{0}(\mathrm{~N} \cdot \mathrm{m})$ brought by bearing lubricant viscosity and friction torque $M_{1}(\mathrm{~N} \cdot \mathrm{m})$ caused by bearing applied force can be calculated by equations (7) and (8):

$$
M_{0}=\left\{\begin{array}{l}
10^{-7} f_{0}\left(v_{0} n\right)^{2 / 3} D_{\mathrm{m}}{ }^{3}, v_{0} n \geq 2000 \\
160 \times 10^{-7} f_{0} D_{\mathrm{m}}{ }^{3}, v_{0} n<2000
\end{array}\right.
$$

In equation (7), $f_{0}$ is a coefficient related to the bearing type and lubrication method, and $v_{0}$ is the kinematic viscosity of the lubricant under working temperature $\left(\mathrm{m}^{2} / \mathrm{s}\right)$.

$$
M_{1}=f_{1} F_{\beta} D_{\mathrm{m}}
$$

In equation $(8), f_{1}$ is a coefficient related to the bearing type and load, $F_{\beta}$ is the bearing load $(\mathrm{N})$, and $D_{\mathrm{m}}$ is the mean diameter of the bearing $(\mathrm{mm})$.

\subsubsection{Screw-nut pair}

When the precision ball screw unit is in operation, the screw-nut pair will generate heat due to its internal friction effect. The heat can be determined by equation (9) [25] and loaded into the simulation modeling of precision ball screw unit.

$$
Q=0.1047 n M_{Z}
$$

In equation (9), $n$ is the rotational speed of ball screw, and $M_{Z}$ is the friction moment of screwnut pair $(\mathrm{N} \cdot \mathrm{m})$, which can be obtained from equations (10)-(12):

$$
M_{\mathrm{Z}}=M_{\mathrm{D}}+M_{\mathrm{P}}
$$




$$
M_{\mathrm{D}}=\frac{F_{\mathrm{a}} P_{\mathrm{h}}}{2 \pi \eta}
$$

$$
M_{\mathrm{p}}=\frac{F_{\mathrm{p}} P_{\mathrm{h}}}{2 \pi \eta}\left(1-\eta^{2}\right)
$$

In equations (10)-(12), $M_{\mathrm{D}}$ and $M_{\mathrm{p}}$ are respectively driving moment and resistance moment of 4 screw-nut pair; $F_{\mathrm{a}}$ is the total axial load of the screw $(\mathrm{kN}) ; F_{\mathrm{p}}$ is the axial preload of the screw-nut 5 pair $(\mathrm{kN}) ; P_{\mathrm{h}}$ is the lead of screw $(\mathrm{mm})$; and $\eta$ is the transmission efficiency of the screw-nut pair.

\subsubsection{Coefficient empirical modeling of ambient and coolant heat convections} [26]:

$$
h_{\mathrm{f}}=\frac{N_{u} K^{*}}{d}
$$

In equation (13), $K^{*}$ is the thermal conductivity of fluid, $d$ is the set size of solid structure. $N_{u}$ 11 is the Nusselt number.

For the ambient air convection occurring at outer surfaces of a long cylinder (screw shaft), the Nusselt number $N_{u}$ is computed from Reynolds number $R e$ and Prandtl number $P r$ :

$$
N u=0.133 \operatorname{Re}^{\frac{2}{3}} \operatorname{Pr}^{\frac{1}{3}}
$$

In equation (14):

$$
\operatorname{Re}=\frac{u_{\text {air }} d}{v_{\text {air }}}
$$

$$
\operatorname{Pr}=\frac{c_{\text {air }} \nu_{\text {air }}}{K^{*}}
$$

For equations (15)-(16), $u_{\text {air }}$ is the air velocity, $v_{\text {air }}$ is the air kinematic viscosity, $c_{\text {air }}$ is the air 
specific heat capacitance.

For the coolant convection occurring inside a tube structure (screw coolant channel), the Nusselt number $N_{u}$ is defined as:

$$
N_{u}=0.15 \operatorname{Re}^{0.33} \cdot \operatorname{Pr}^{0.43} \cdot G r^{0.1} \cdot\left(\operatorname{Pr} / \operatorname{Pr}_{w}\right)^{0.25} \cdot K
$$

In equation (17), $R e$ is the Reynods number, $P r$ is the Prandtl number, $G r$ is the Grashof number, $P r_{w}$ is the Prandtl number of contact surface, and $K$ is the correction coefficient.

In addition, stationary surfaces of precision ball screw unit mainly interact with ambient air by natural convection and its heat transfer coefficient $h=9.7 \mathrm{~W} / \mathrm{m}^{2} \cdot \mathrm{K}$ is provided by Reference [26].

\subsubsection{Thermal load optimization and correction method}

Generally, thermal simulation loads obtained by empirical formula has errors compared with their actual values. Therefore, based on the simulation model above, genetic algorithm is adopted to comprehensively optimize and modify heat generation values of bearing groups, screw-nut pair and convection heat transfer coefficients. The modified values of them are taken as the thermal loads, for accurate thermal simulation model of precision ball screw unit. The optimization method is described in Fig. 8.

As described in Fig. 8, the empirical values of heat generating parts and convection heat transfer coefficients are used as initial values of design variables. These values are adopted for heat-fluidsolid coupling simulation of precision ball screw unit. Thus multi-physical field models of heat transfer, fluid and structural mechanics in transient simulation are considered as the constraint conditions. The overall errors between simulated structural temperatures of precision ball screw unit and the corresponding experimental data are designed as the fitness function, and the objective function is to minimize these overall errors. That means thermal load values will be continuously updated by genetic algorithm until the overall errors meet the requirement. With this optimization and correction process, the exact thermal loads and simulated structural temperature of precision ball screw unit are obtained. 
14 Experimental verification of the advantages of active coolant control strategy in correcting

2 thermal elongation of screw shaft

$3 \quad 4.1$ Experimental method

\subsubsection{Monitoring method onto thermal elongation of screw shaft}

In this paper, the shaft thermal elongation of precision ball screw unit can be experimentally reflected according to the thermal variations of the positioning errors of machine feed system (Grating encoder is closed), which is monitored by the laser interferometer in Fig. 9.

From the initial moment of each experiment, positioning errors of machine feed system is tested by laser interferometer every hour for the 2-hours operation. Then the differences from the detected values at 1-hour/2-hour moments to the initial moment are calculated respectively, to obtain the thermal variations of the machine positioning errors at these 2 moments. According to engineering experience, thermal variations above are mainly attributed to thermal elongations of screw shaft, which can be influenced by the applications of different screw coolant control strategies.

\subsubsection{Design of comparative experiments}

In order to verify the effectiveness and advantages of the proposed active coolant control strategy in correcting the thermal elongations of screw shaft, comparative experiments are necessary: the precision ball screw unit operated under the proposed active coolant control strategy and the traditional ambient temperature tracking strategy respectively.

Besides, both of experiments were carried out under the same working conditions: 1 . Worktable moving speed of machine feed system is $9 \mathrm{~m} / \mathrm{min} ; 2$. Each experiment lasts for 2 hours (7200s); 3 . Ambient temperature is $17^{\circ} \mathrm{C}$ initially, and then increase slowly by $2{ }^{\circ} \mathrm{C}$ during the whole operation; 4. Coolant supply flow rate for each precision ball screw unit is $7.5 \mathrm{~L} / \mathrm{min}$.

\subsection{Experimental results and discussions}

\subsubsection{Accurate screw structural temperature rises based on simulation load correction}


After the correction procedure in Section 3.2, obtained loading values and their corresponding loading positions for the thermal simulation model of precision ball screw unit are listed in Tab. 2 .

Based on these corrected thermal loads, simulated temperature rises of screw heat generating parts are obtained under the active coolant control and ambient temperature tracking strategies respectively. These simulated temperatures are compared with their corresponding measured values in experiments, which is shown in Fig. 10. It can be seen that the simulated curves and the experimental curves are very close to each other under both 2 strategies respectively. Therefore, it can be concluded that the established simulation models can accurately reflect actual thermal behaviors of precision ball screw unit, which provides the possibility to observe its structural temperature to verify the empirical model in Section 2.2.1.

\subsubsection{Structural temperature discussions of precision ball screw unit (empirical model verification of active coolant control strategy)}

The accurate simulated structural temperature rises of precision ball screw unit obtained above are compared with screw coolant temperature rises detected by RTD sensors. As illustrated in Fig. 11 , this comparison is for both the active coolant control strategy and ambient temperature tracking strategy: the structural temperatures of precision ball screw unit are very close to those of coolants, which proves the reliability of the empirical model proposed in Section 2.2.1 (equation (2)).

It can be observed from Figs. 11 (a) and (b) that, coolant temperature is always slightly lower than the screw structural temperature. That is because the time-increasing ambient temperature and heat generations of screw-nut pair / bearings have the heating effect onto screw shaft, and cause its temperature rises. To make screw shaft temperature approach to coolant temperature, recirculating coolant has the cooling effect onto it. Owing to the intensive heat convention effect of recirculation coolant, screw shaft temperatures can be stabilized in time by real time heat dissipations of coolant.

In addition, as shown in Fig. 11 (a), with the ambient temperature rising from $17^{\circ} \mathrm{C}-19^{\circ} \mathrm{C}$, the structural and coolant temperatures of precision ball screw unit remain approximately at their initial values. However, in Fig. 11 (b), they continue to rise following the ambient temperature rising. This fact indicates that the screw structural temperature caused by the ambient temperature tracking strategy is seriously affected by variations of ambient temperature, but the active coolant control 
1 strategy is more effective in resisting thermal influence from variations of ambient temperature

2 onto screw structural temperature.

$3 \quad$ 4.2.3 Thermal elongation discussions of screw shaft (Advantage verification of active coolant control strategy)

Thermal variations of positioning errors of machine feed system generated by the active coolant control strategy and the ambient temperature tracking strategy are detected by the method in Section 4.1.1. They can reflect the shaft thermal elongations of precision ball screw unit caused by these 2 strategies.

As illustrated in Fig. 12 that, thermal variations of machine positioning error caused by the active coolant control strategy are smaller than $10 \mu \mathrm{m}$, while that caused by ambient temperature tracking strategy continues to increase with time and is significantly greater than the former. This is attributed to the structural temperature difference of precision ball screw unit, which is conveyed by Fig. 11: its structural temperature caused by the active coolant control strategy is more stable than that caused by the ambient temperature tracking strategy.

It can be concluded that the proposed active coolant control strategy is more advantageous than traditional one, in correcting shaft elongation of precision ball screw unit and ensuring accuracy stabilization of machine feed system.

\section{Conclusions}

In order to resist thermal disturbances from internal heat generations and external ambient temperature change of precision ball crew unit onto its structural thermal behaviors, an active coolant control strategy is proposed in this paper. This method controls the coolant temperature of precision ball screw unit to keep stable, thus to stabilize the screw shaft temperature and correct its thermal elongation. The conclusions of this study are as follows:

1). Compared with the traditional ambient temperature tracking method, the proposed active coolant control method is more advantageous in structural temperature stabilization and thermal elongation correction of precision ball screw unit. This is verified by comparative experiments. 
2). The empirical model for the active coolant control strategy is verified to be reliable by the experimental and simulation results: For the slender and long tubular structure of screw shaft, the screw shaft temperature is approximately equal to its recirculating coolant temperature, owing to the intensive coolant forced thermal convection onto screw shaft.

\section{Acknowledgement}

Authors acknowledge the Fund of National Nature Science Foundation of China (No.51775375) and Open Fund of Jiangsu Key Laboratory of Precision and Micro-Manufacturing Technology. 


\section{Declarations}

\section{-Ethical Approval}

$3 \quad$ Not applicable.

\section{$4 \quad$-Consent to Participate}

5 All authors are consent to participate in the author team of this submitted manuscript.

\section{$6 \quad$-Consent to Publish}

$7 \quad$ The submitted manuscript is approved by all its authors for publication.

\section{-Authors Contributions}

Teng Liu proposed and described the active coolant control strategy for thermal behaviors of precision ball crew unit, based on an empirical model: For the slender and long tubular structure of

11 screw shaft, the screw shaft temperature is approximately equal to its recirculating coolant 12 temperature.

13 Chentao Li finished the finite element simulation modeling about thermal behaviors of precision 14 ball screw unit, and then performed the contrasting experiments for this study. The aim is to verify 15 the reliability of the empirical model above and the advantages of the active coolant strategy. 16 Meanwhile, he finished the handwriting of the manuscript as a whole.

17 Yifan Zhang constructed the controlling algorithm for this study, and then finished the data 18 analyses about experimental and simulation results.

19 Weiguo Gao gave Teng Liu the significant guidance about the thermal simulation modeling 20 method of precision ball screw unit.

21 Zhikai Fu finished the construction of experimental platform.

22 Jianjun Zhang designed the logical structure of the whole manuscript. 
1 Dawei Zhang gave crucial comments onto this work for improving its technical route.

$2 \quad$-Funding

3 The research was supported by the Fund of National Nature Science Foundation of China

4 (No.51775375) and Open Fund of Jiangsu Key Laboratory of Precision and Micro-Manufacturing

5 Technology.

$6 \quad$-Competing Interests

$7 \quad$ No conflict of interest exits in the submission of this manuscript.

$8 \quad$-Availability of data and materials

$9 \quad$ Data generated or analyzed in this study are available.

10 


\section{References}

[1] Weck M, McKeown P, Bonse R, Herbst U (1995) Reduction and Compensation of Thermal errors in Machine Tools. CIRP Ann - Manuf Technol 44(2): 589-598

[2] Chou C, Debra DB (1990) Liquid temperature control for precision tools. CIRP Ann - Manuf Technol 39(1): 535-543

[3] Mao XB, Mao KM, Wang FY, Yan B, Lei S (2018) A convective heat transfer coefficient algorithm for thermal analysis of machine tools considering a temperature change. Int J Adv Manuf Tech 99(5-8): 1877-1889

[4] Oyanguren A, Larranaga J, Ulacia I (2018) Thermo-mechanical modelling of ball screw preload force variation in different working conditions. Int J Adv Manuf Tech 97(1-4): 723-739

[5] Li Y, Wei WM, Su DX, Wu WW, Zhang J, Zhao WH (2020) Thermal characteristic analysis of ball screw feed drive system based on finite difference method considering the moving heat source. Int J Adv Manuf Tech 106(9-10): 4533-4545

[6] Li TJ, Sun TY, Zhang YM, Zhao CY (2021) Prediction of thermal error for feed system of machine tools based on random radial basis function neural network. Int J Adv Manuf Tech 114(56): $1545-1553$

[7] Li ZJ, Zhao CY, Lu ZC (2020) Thermal error modeling method for ball screw feed system of CNC machine tools in X-axis. Int J Adv Manuf Tech 106(11-12): 5383-5392

[8] Li TJ, Zhao CY, Zhang YM (2019) Prediction method of thermal errors of the screw system in lathes based on moving thermal network. Precis Eng-J Int Soc Precis Eng Nanotechnol 59: 166173

[9] Shi H, Jiang CP, Yan ZZ, Tao T, Mei XS (2020) Bayesian neural network-based thermal error modeling of feed drive system of CNC machine tool. Int J Adv Manuf Tech 108(9-10): 3031-3044

[10] Gao F, Hei CF, Liu JF, Li Y, Shui LQ (2021) Synthetic positioning error modelling of a feed axis for a precision CNC machine tool. Int J Adv Manuf Tech 114(5-6): 1385-1394 
[11] Yang HJ, Xing RP, Du FX (2020) Thermal error modelling for a high-precision feed system in varying conditions based on an improved Elman network. Int J Adv Manuf Tech 106(1-2): 279288

[12] Zaplata J, Pajor M (2019) Piecewise compensation of thermal errors of a ball screw driven CNC axis. Precis Eng-J Int Soc Precis Eng Nanotechnol 60: 160-166

[13] Shen HY, Fu JZ, He Y, Yao XH (2012) On-line Asynchronous Compensation Methods for static/quasi-static error implemented on CNC machine tools. Int J Mach Tools Manuf 60: 14-26

[14] Bosetti P, Bruschi S (2012) Enhancing positioning accuracy of CNC machine tools by means of direct measurement of deformation. Int J Adv Manuf Tech 58(5-8): 651-662

[15] Ge Z, Ding XH (2018) Thermal error control method based on thermal deformation balance principle for the precision parts of machine tools. Int J Adv Manuf Tech 97(1-4): 1253-1268

[16] Wei XY, Miao EM, Wang W, Liu H (2019) Real-time thermal deformation compensation method for active phased array antenna panels. Precis Eng-J Int Soc Precis Eng Nanotechnol 60: $121-129$

[17] Mayr J, Jedrzejewski J, Uhlmann E, Alkan Donmez M, Knapp W, Hartig F, Wendt K, Moriwaki T, Shore P, Schmitt R, Brecher C, Wurz T, Wegener K (2012) Thermal issues in machine tools. CIRP Ann - Manuf Technol 61(2): 771-791

[18] Zhang YF, Wang P, Liu T, Gao WG, Chang WF, Tian YL, Zhang DW (2018) Active and intelligent control onto thermal behaviors of a motorized spindle unit. Int J Adv Manuf Tech 98(912): $3133-3146$

[19] Liu T, Zhou L, Gao WG, Zhang YF, Chang WF, Zhang JJ, Zhang DW (2021) Thermal simulation speculation-based active coolant control onto spindle bearings. Int J Adv Manuf Tech 113(1-2): $337-350$

[20] Liu T, Gao WG, Tian YL, Zhang HJ, Chang WF, Mao K, Zhang DW (2015) A differentiated multi-loops bath recirculation system for precision machine tools. Appl Therm Eng 76: 54-63 
[22] Datta A, Ho MT, Bhattacharyya SP (2000) Structure and Synthesis of PID Controllers.

3 Spinger-Verlag Press

[23] John DA (1995) Computational fluid dynamics: the basics with applications. McGraw Hill

5 [24] Li DX, Feng PF, Zhang JF, Wu ZJ, Yu DW (2014) Calculation method of convective heat 6 transfer coefficients for thermal simulation of a spindle system based on RBF neural network. Int $7 \quad$ J Adv Manuf Tech 70(5-8): 1445-1454

8 [25] Rong L, Wei L, Zhang J, Chen Z, Shuang Q (2018) Research on thermal deformation of 9 feed system for high-speed vertical machining center. Procedia Computer Science 131: 469-476

10 [26] Xu M, Jiang S, Cai Y (2007) An improved thermal model for machine tool bearings. Int J 11 Adv Manuf Tech 47: 53-62 


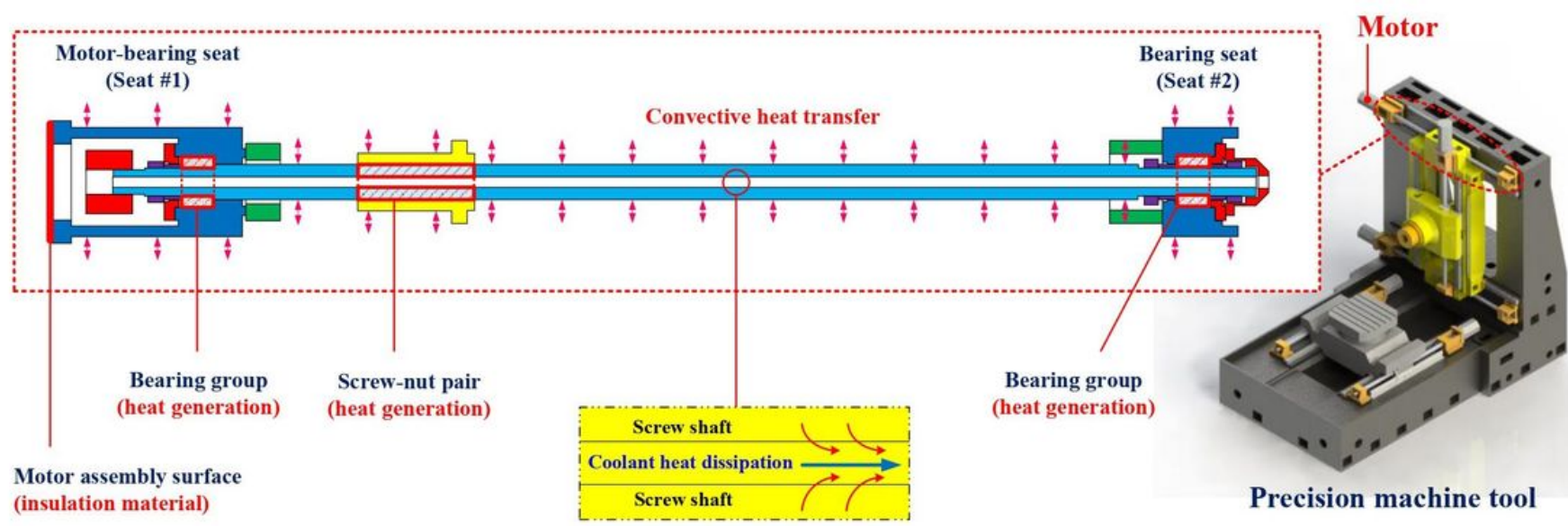

\section{Figure 1}

Influencing factors onto structural thermal behaviors of precision ball screw unit

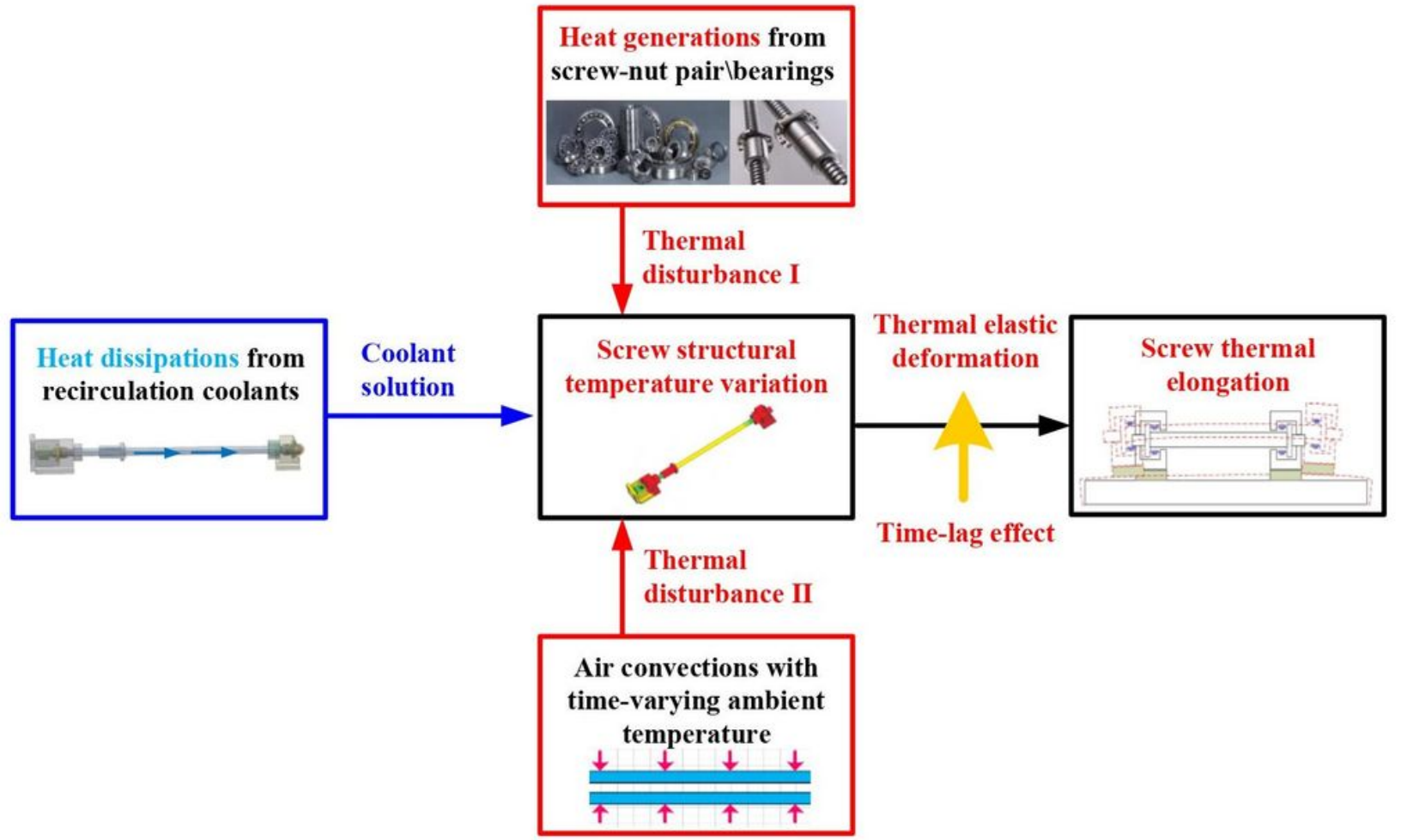

Figure 2 


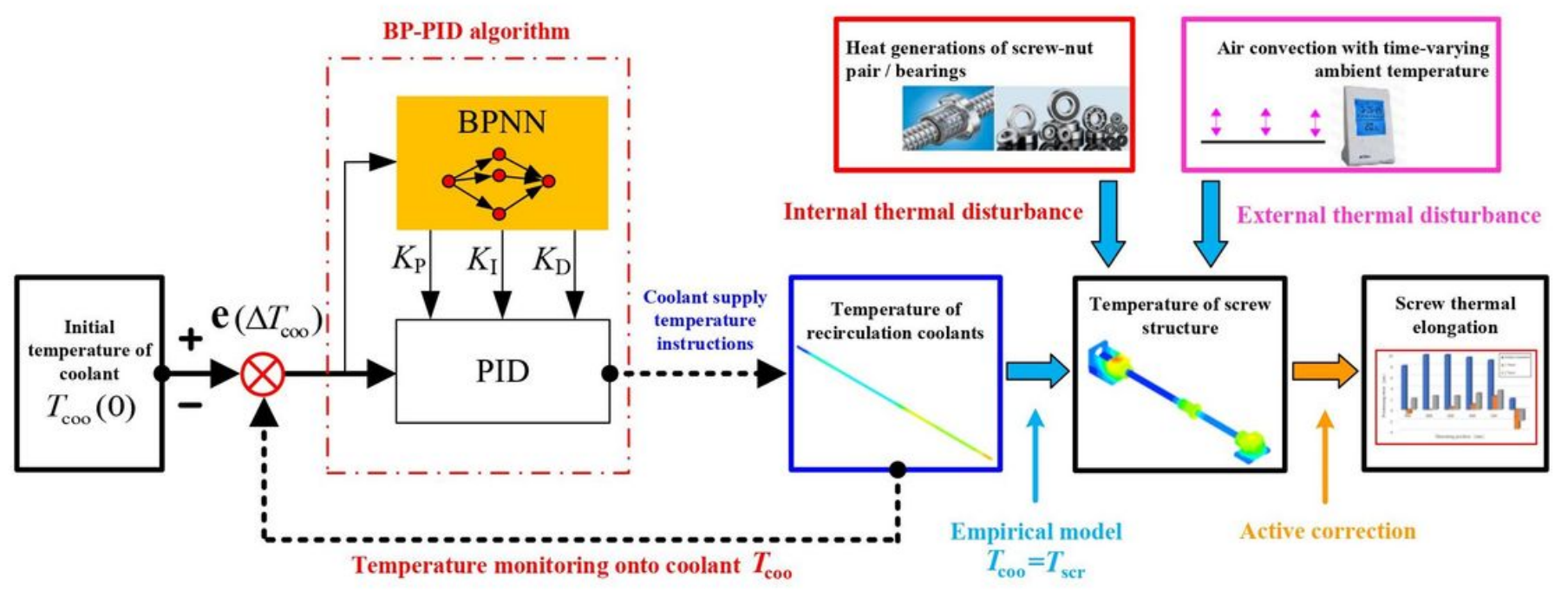

Figure 3

Description of active coolant control strategy onto structural thermal behaviors of precision ball screw unit

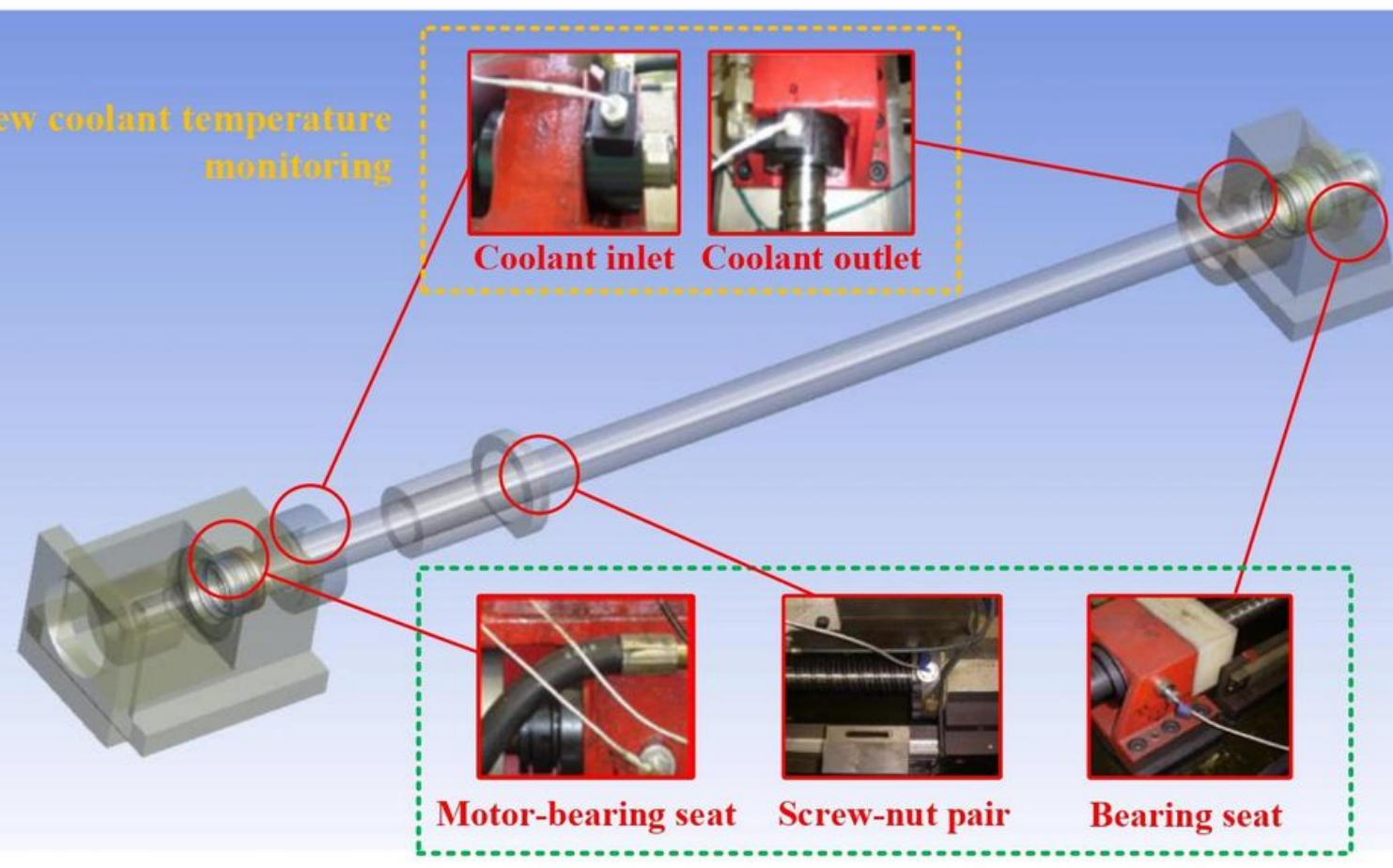

Screw structure temperature monitoring

Figure 4

RTD sensors for precision ball screw unit 


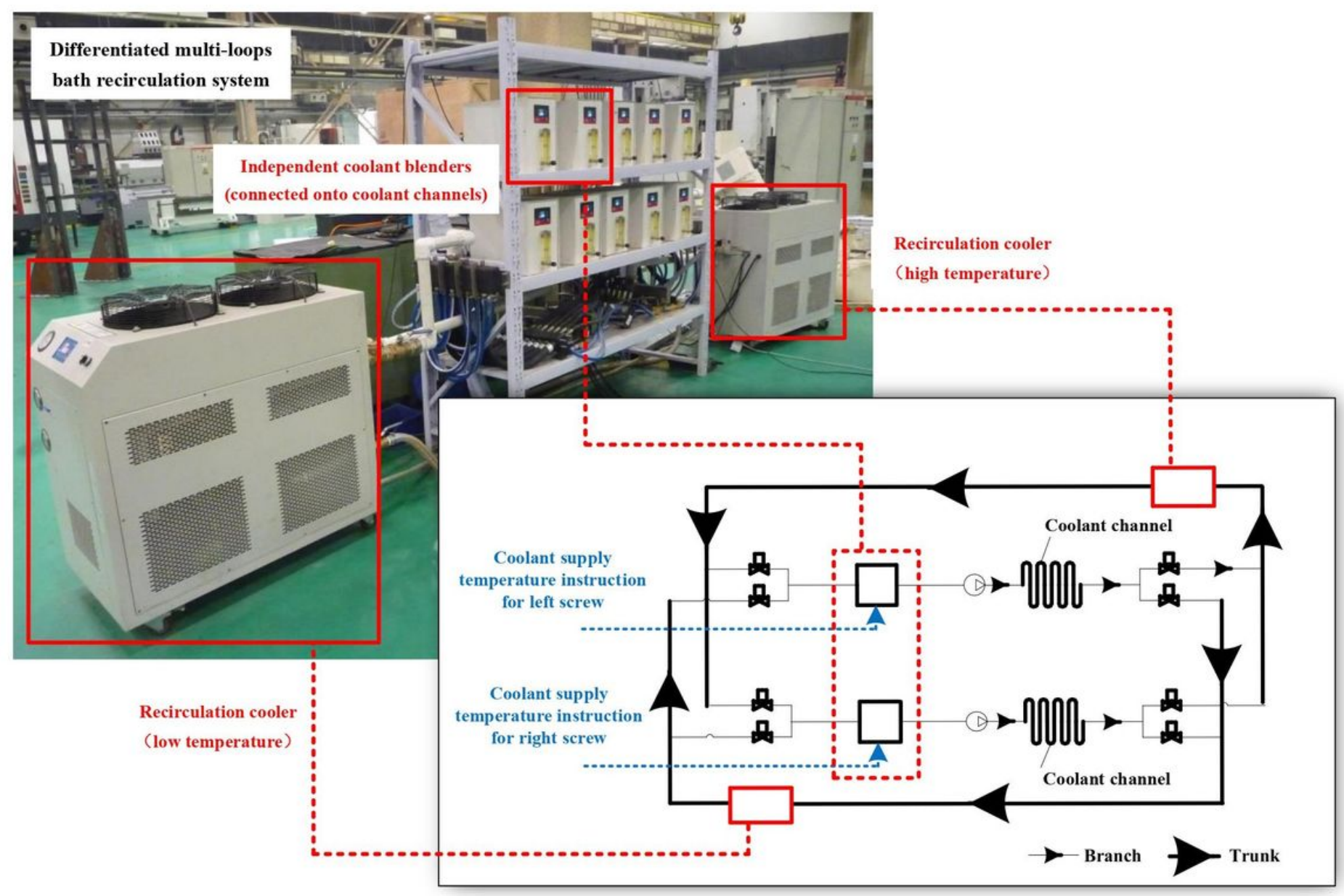

Figure 5

Screw coolant channels equipped with differentiated multi-loops bath recirculation system 


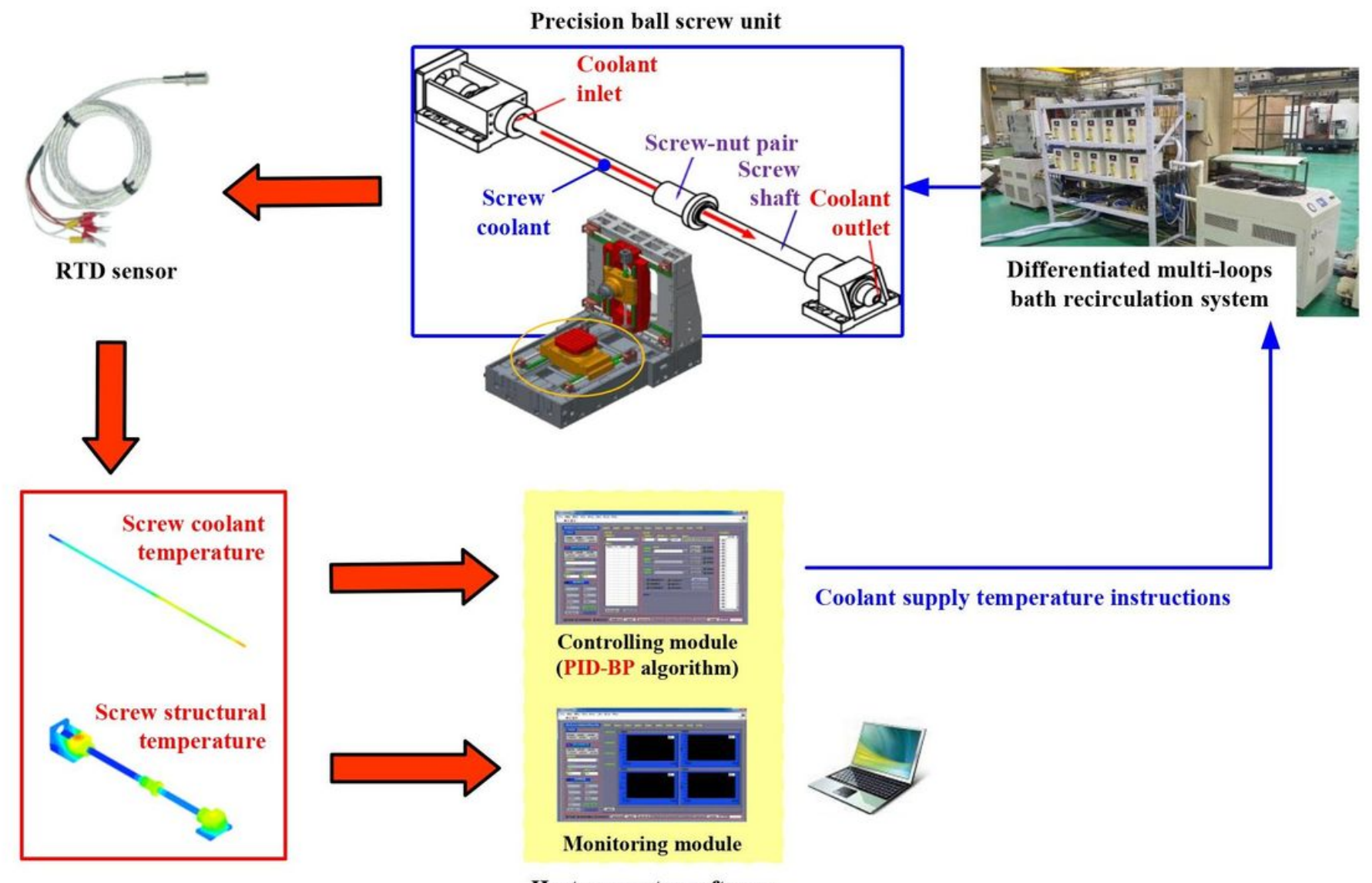

Host computer software

Figure 6

Active coolant control platform for thermal behaviors of precision ball screw unit 


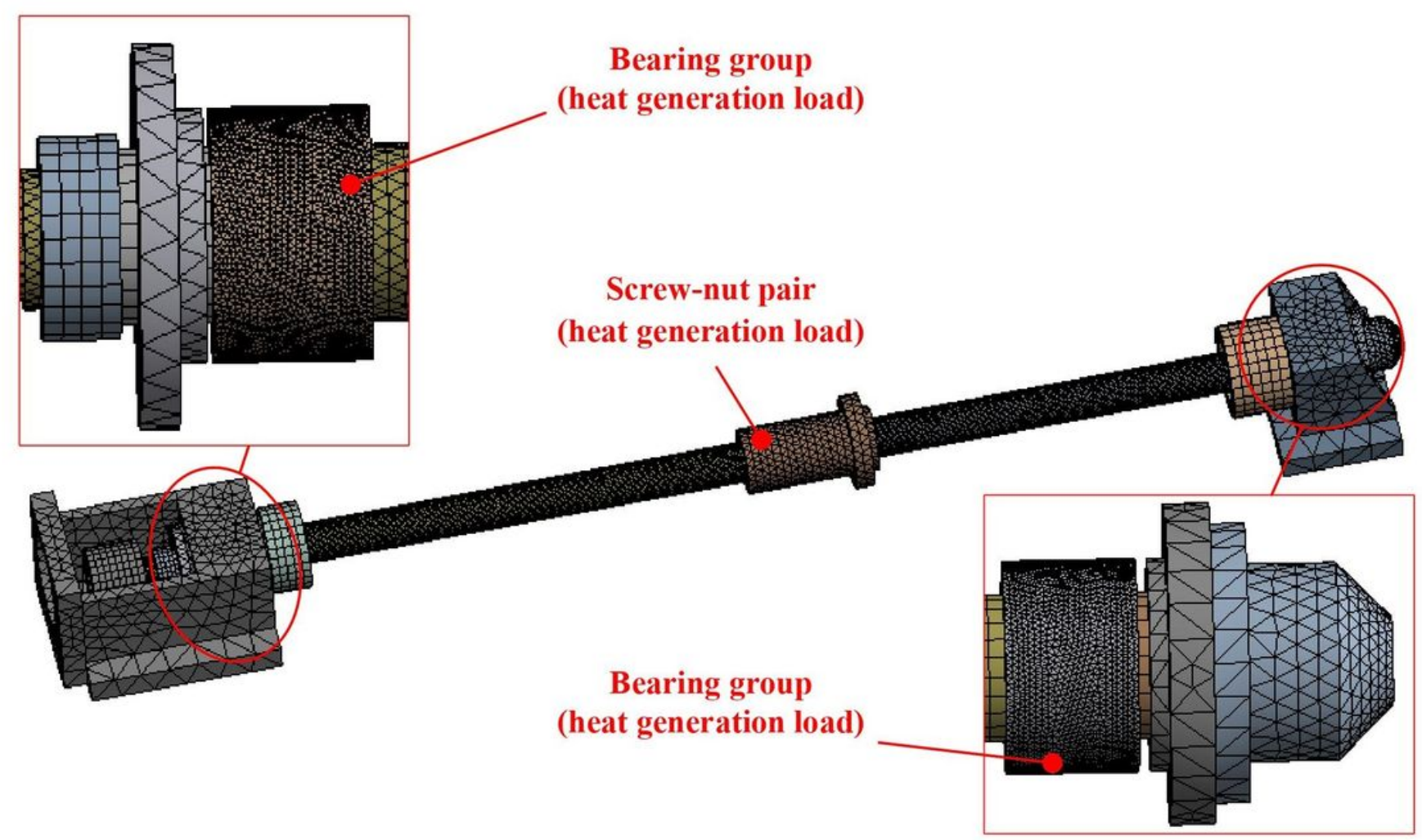

Figure 7

Heat generation loads for FE simulation of precision ball screw unit 


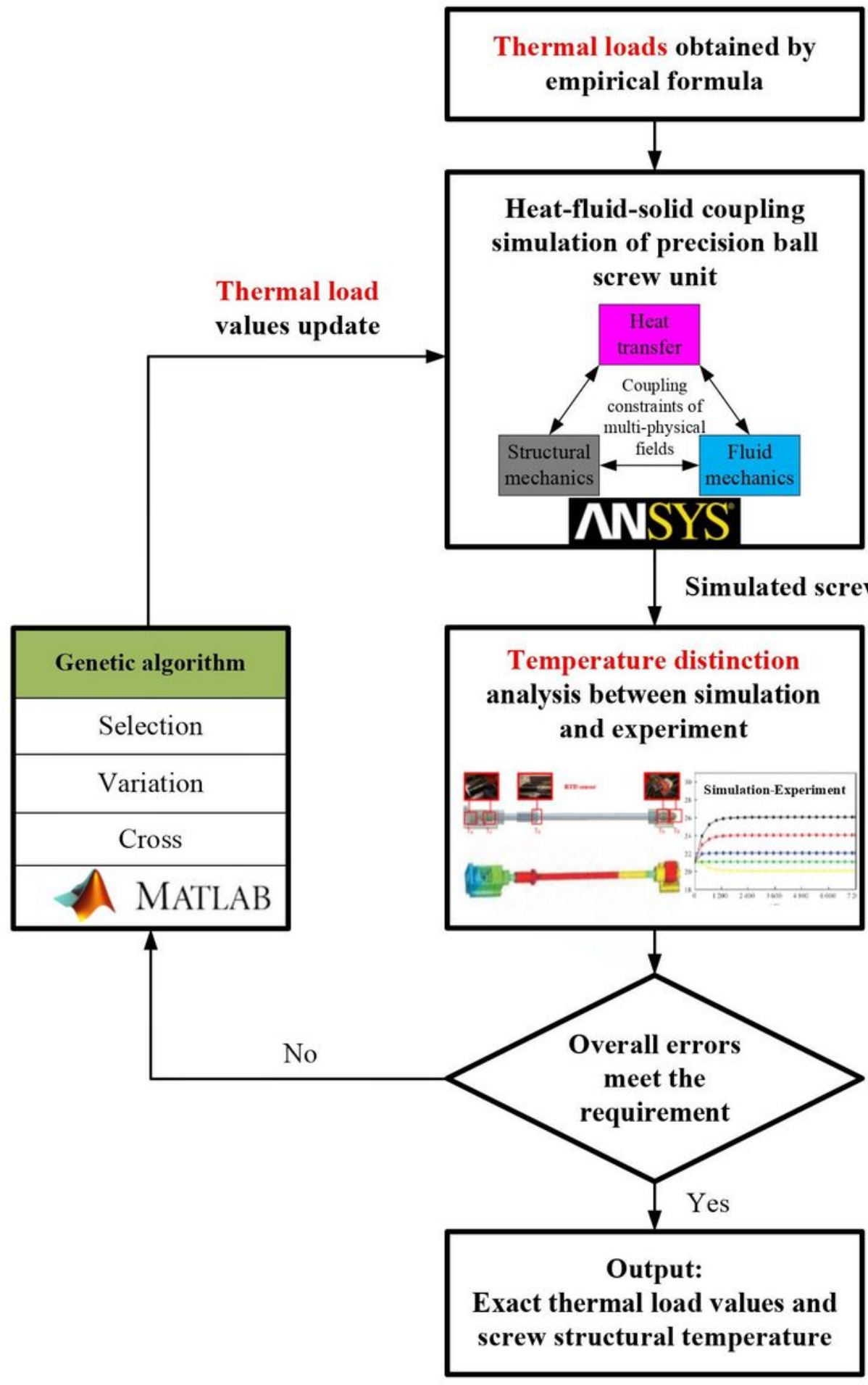

Figure 8

Genetic algorithm based thermal load optimization and correction method 


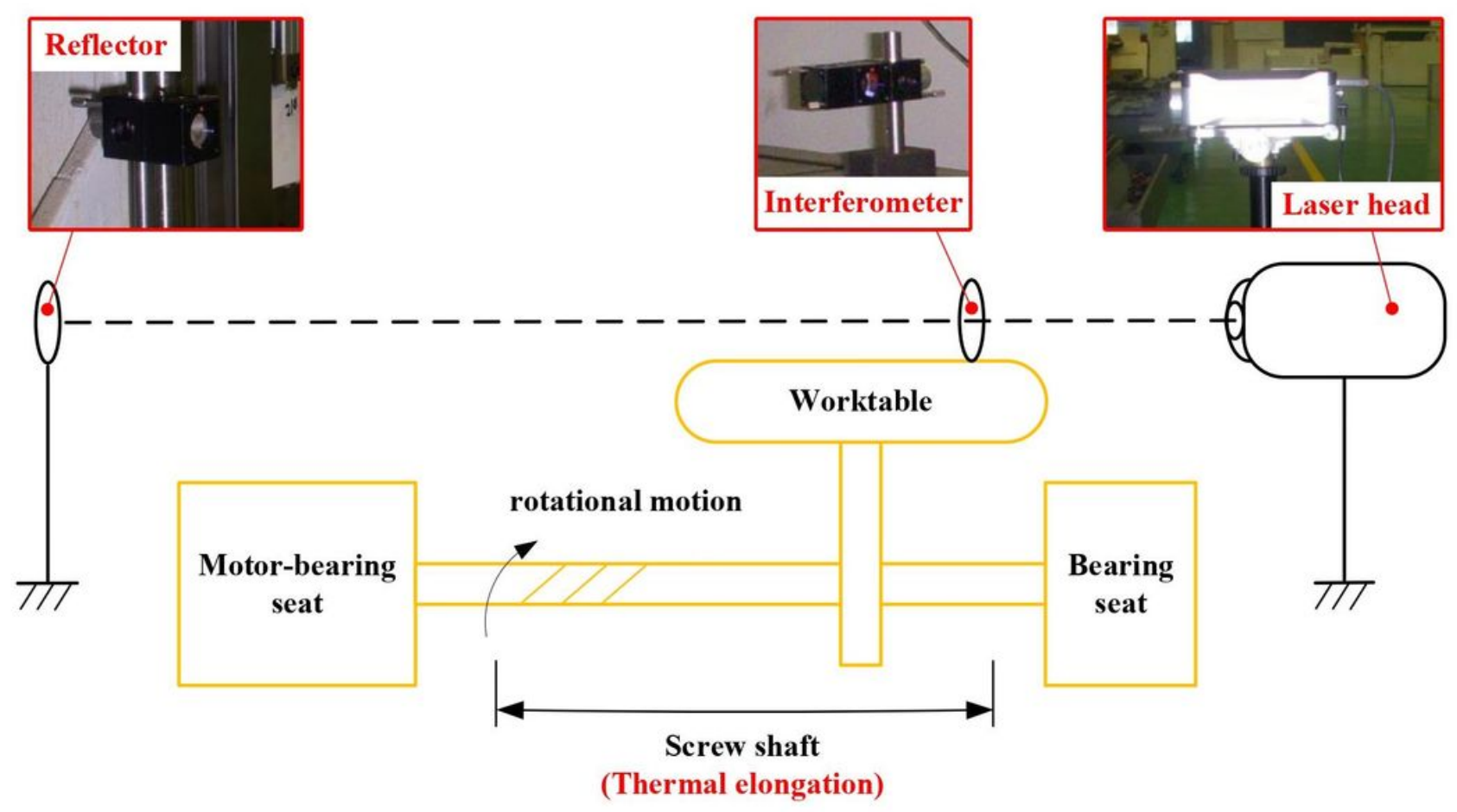

Figure 9

Laser interferometer for monitoring thermal elongation of screw shaft 


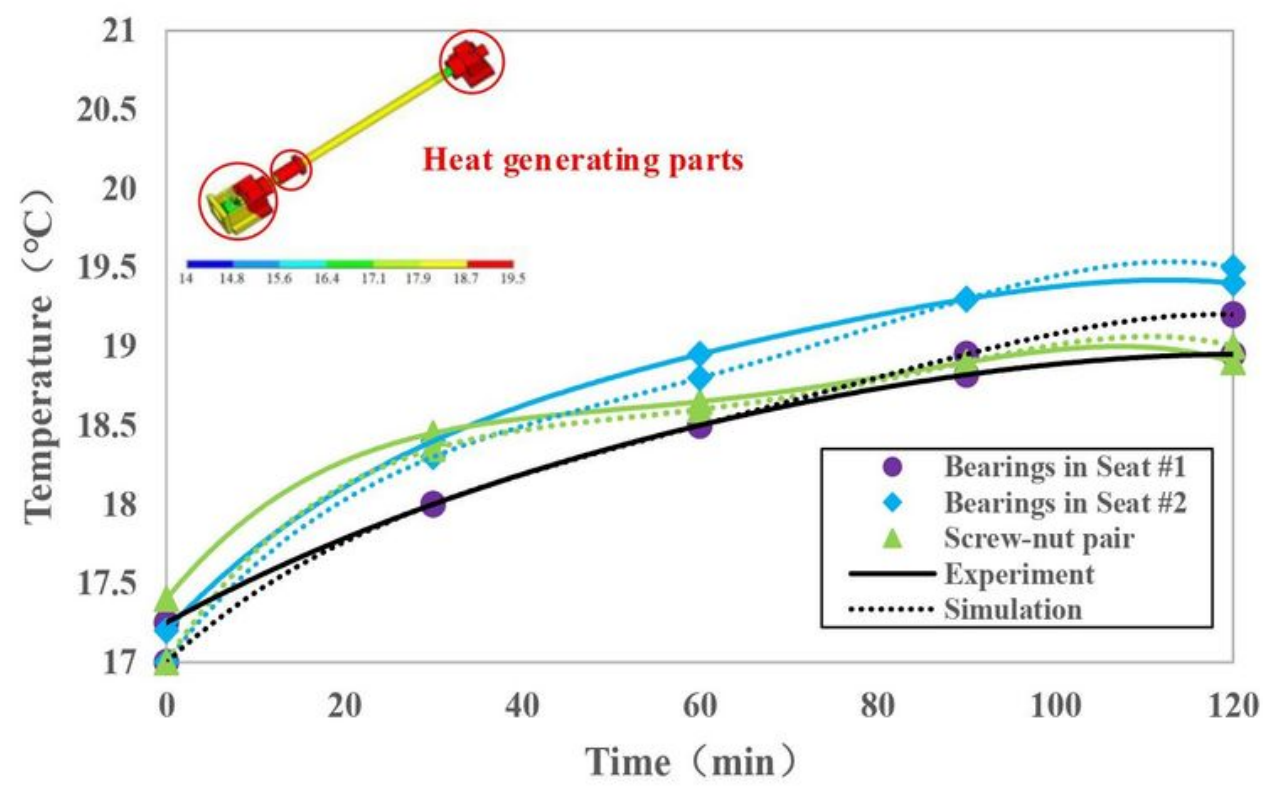

(a). Active coolant control strategy

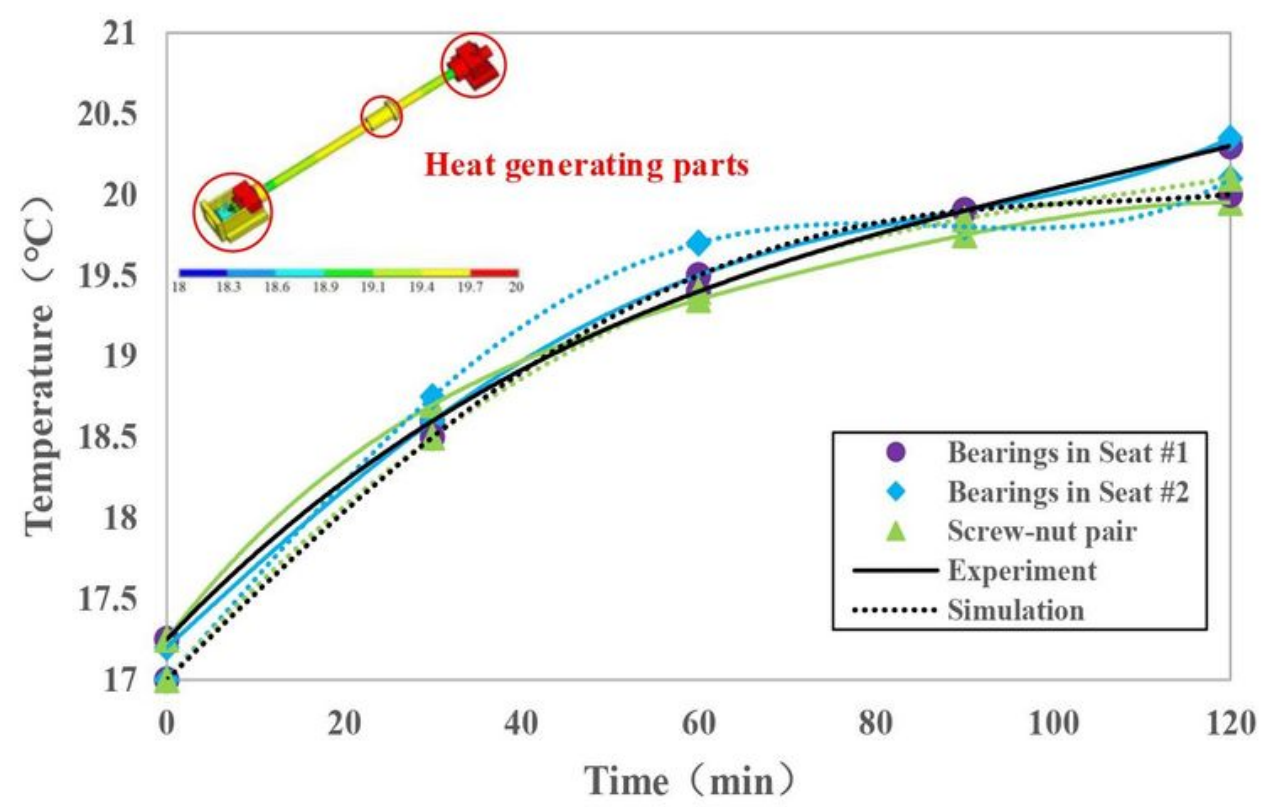

(b). Ambient temperature tracking strategy

\section{Figure 10}

Comparison between simulated screw temperature rises (based on thermal load corrections) and their corresponding experimental data 


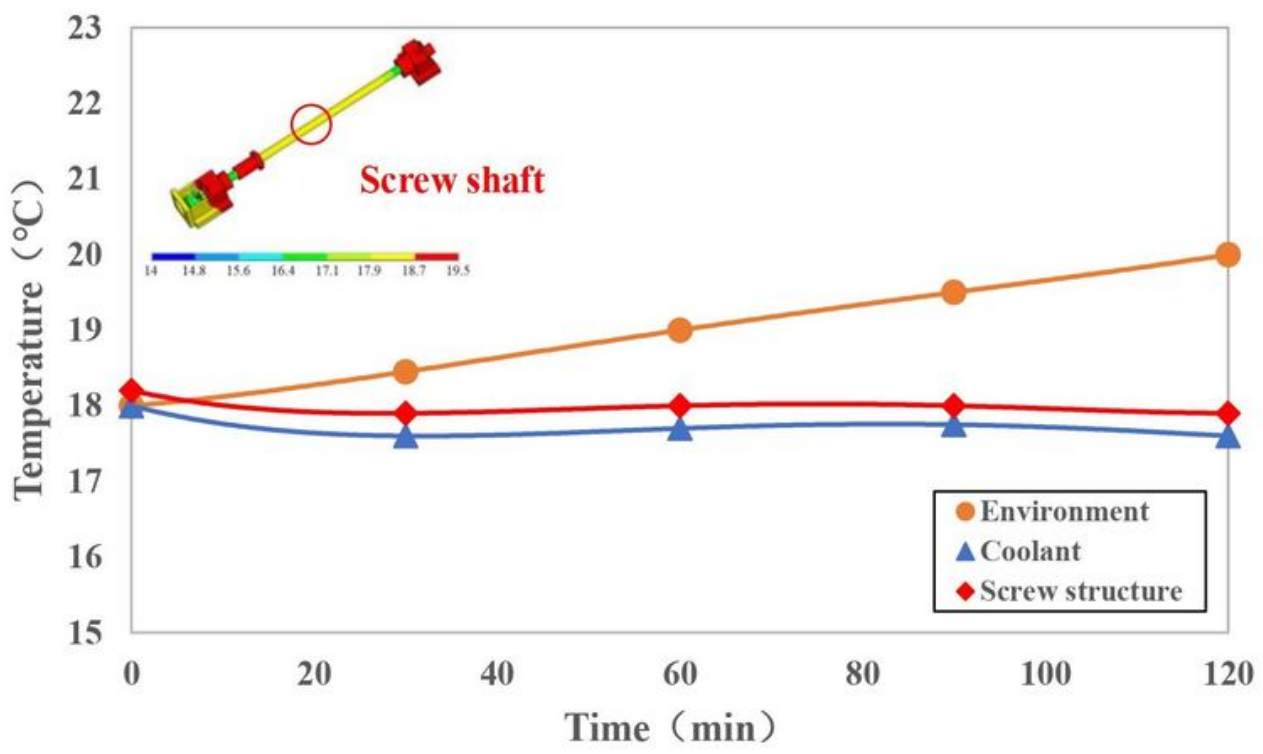

(a). Active coolant control strategy

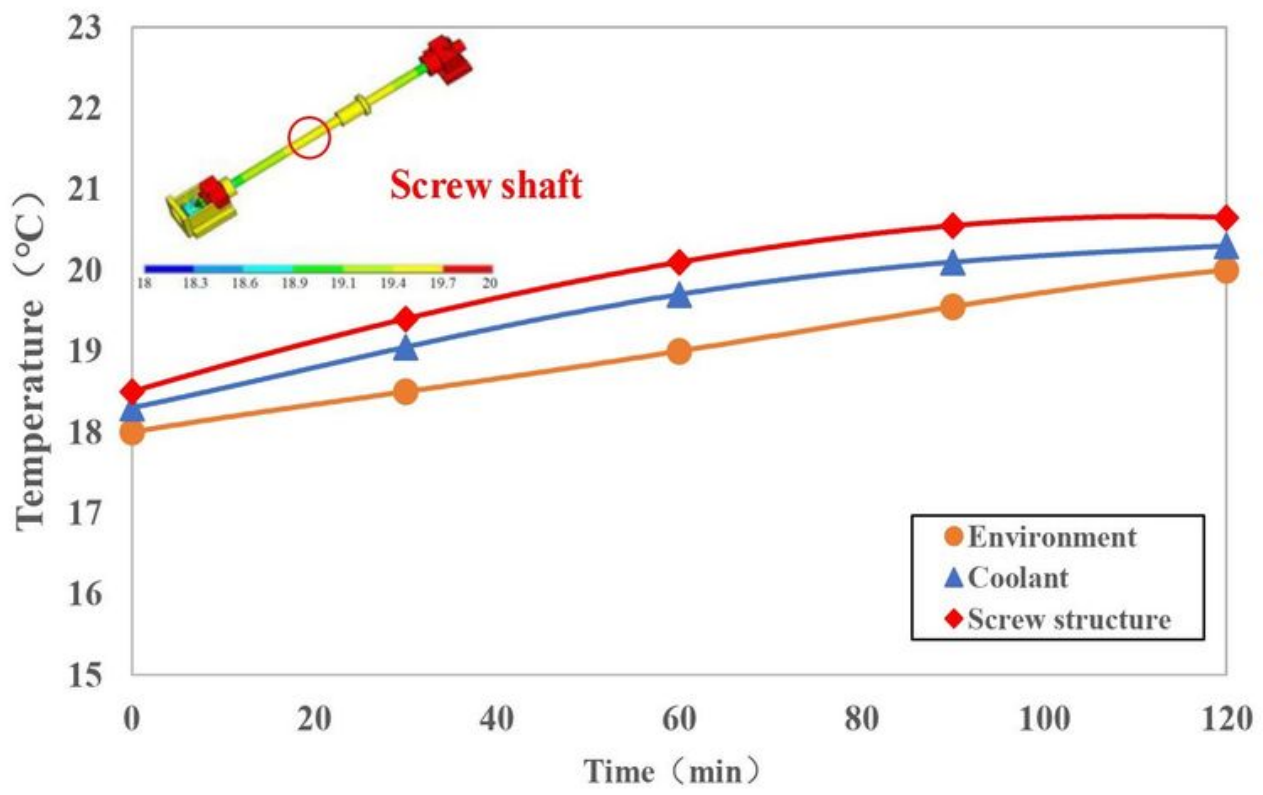

(b). Ambient temperature tracking strategy

\section{Figure 11}

Comparison between simulated screw structural temperature and coolant temperature detected in experiments 


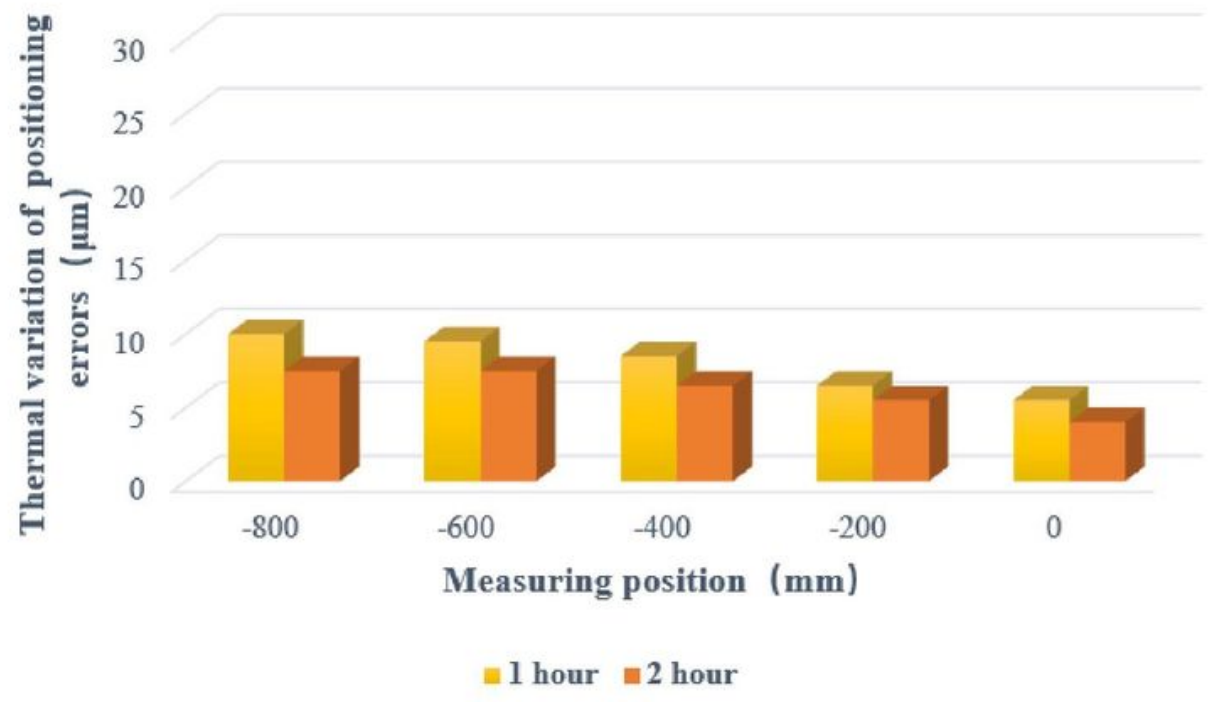

(a). Active coolant control strategy



(b). Ambient temperature tracking strategy

Figure 12

Comparison of shaft thermal elongations of precision ball screw unit 